\title{
A Highly Selective and Sensitive Detection of Ellagic Acid by Using Ethylenediamine Ligand Based Cobalt (II) Complex Modified Glassy Carbon Electrode
}

Subramanian Sakthinathan ${ }^{1}$, Thangavelu Kokulnathan ${ }^{1}$, Shen-Ming Chen ${ }^{1, *}$, Tse-Wei Chen ${ }^{1,2}$, Tien-Wen Tseng ${ }^{2}$, Xiaoheng Liu ${ }^{3, *}$, Wei Cheng Liao ${ }^{1}$

${ }^{1}$ Electroanalysis and Bioelectrochemistry Lab, Department of Chemical Engineering and Biotechnology, National Taipei University of Technology, No.1, Section 3, Chung-Hsiao East Road, Taipei 106, Taiwan (R.O.C).

${ }^{2}$ Department of Chemical Engineering and Biotechnology, National Taipei University of Technology, No.1, Section 3, Chung-Hsiao East Road, Taipei 106, Taiwan (R.O.C)

${ }^{3}$ Key Laboratory of Education Ministry for Soft Chemistry and Functional Materials, Nanjing University of Science and Technology, Nanjing 210094, China.

*E-mail: smchen78@ms15.hinet.net, xhliu@mail.njust.edu.cn

doi: $10.20964 / 2017.07 .89$

Received: 23 March 2017 / Accepted: 24 May 2017 / Published: 12 June 2017

We have successfully prepared simple and sensitive ethylenediamine ligand based cobalt (II) inorganic complex $\left(\left[\mathrm{Co}(\mathrm{en})_{3}\right]^{2+}\right)$ (en = ethylenediamine) modified glassy carbon electrode (GCE) and used for the electro chemical detection of Ellagic acid (EA). The prepared inorganic complex was characterized by the suitable physical and chemical characterization technique. Moreover, the modified electrode performance was monitored by the cyclic voltammetric $(\mathrm{CV})$ and amperometric technique (it). Besides, the $\mathrm{GCE} /\left[\mathrm{Co}(\mathrm{en})_{3}\right]^{2+}$ electrode has remarkably enhance the electrocatalytic activity towards the detection of EA. Using the optimized condition, the sensor exhibited the linear detection response range $(0.1 \mu \mathrm{M}-929 \mu \mathrm{M})$ with the limit detection $(0.035 \mathrm{nM})$ and the sensitivity is $\left(0.06709 \mu \mathrm{A} \mu \mathrm{M} \mathrm{cm}^{-}\right.$ ${ }^{2}$ ). Furthermore, the fabricated electrode is an exhibited the acceptable repeatability, reproducibility and stability. On the other hand, the GCE/ $\left[\mathrm{Co}(\mathrm{en})_{3}\right]^{2+}$ modified electrodes have been applied for the real sample analysis, which exhibit the acceptable recovery. The practical application of the modified electrode was successfully applied for the determination of EA from the real samples with good recovery.

Keywords: Ellagic acid, Electrochemical sensor, Cobalt complex, Real sample analysis, Limit of detection. 
(C) 2017 The Authors. Published by ESG (www.electrochemsci.org). This article is an open access article distributed under the terms and conditions of the Creative Commons Attribution license (http://creativecommons.org/licenses/by/4.0/). 